follow-up. The present study found that $19 \%$ of patients with conversion disorder also had depression, but it did not examine physical illness. The results of the two studies regarding depressive disorder are similar.

Finally, Lancman et al (1994) examined the presence of comorbidity among patients with conversion disorder and reported that $48 \%$ of the sample were taking anticonvulsants. The results of the present study regarding comorbidity of epilepsy with conversion disorder are in line with these findings.

\section{Conclusions}

Conversion disorder is more common in married women with a family history of psychiatric disorder. High levels of psychiatric comorbidity exist with conversion disorder. Emphasis must be given to the better use of neurodiagnostic tools for the evaluation and the management of comorbidity. Further studies are required to explore this aspect.

\section{References}

American Psychiatric Association (1980) Diagnostic and Statistical Manual of Mental Disorders (3rd edn) (DSM-III). Washington, DC: APA.

American Psychiatric Association (1994) Diagnostic and Statistical Manual of Mental Disorders (4th edn) (DSM-IV). Washington, DC: APA.
Crimlisk, H. L., Bhatia, K., Cope, H., et al (1998) Slater revisited: 6 year follow up study of patients with medically unexplained motor symptoms. BMJ, 316, 582-586.

Ettinger, A. B., Devinsky, O., Weisbrot, D. M., et al (1999) A comprehensive profile of clinical, psychiatric and psychosocial characteristics of patients with psychogenic nonepileptic seizures. Epilepsia, 40, 1292-1298.

Kapfhammer, H. P., Buchheim, P., Bove, D., et al (1992) Conversion symptoms of patients in psychiatric liaison care. Nervenarzt, 63, 527-538.

Kaplan, H. I. \& Sadock, B. J. (2004) Somatoform disorders. In Synopsis of Psychiatry (8th edn), pp. 629-645. Baltimore, MD: W illiams and W ilkins.

Lancman, M. E., Asconape, J. J., Graver, S., et al (1994) Psychogenic seizures: long term analysis of 43 cases. Journal of Neurology, 9, 404-407.

Mace, C. J. \& Trimble, M. R. (1996) Ten year prognosis of conversion disorder. British Journal of Psychiatry, 169, 282288.

Pehlivanturk, B. \& Unal, F. (2002) Conversion disorder in children and adolescents: a 4-year follow-up study. Journal of Psychosomatic Research, 52, 187-191.

Ron, M. A. (1994) Somatisation in neurological practice. Journal of Neurology, Neurosurgery and Psychiatry, 57, 1161- 1166 .

Scheidt, C. E., Koster, B. \& Deuschl, G. (1992) Diagnosis, symptoms and follow up of psychogenic tremor. Nervenarzt, 63, 527-538.

Spierings, C., Poels, P. J., Sijben, N., et al (1998) Conversion disorders in childhood: a retrospective follow-up study of 84 inpatients. International Journal of Clinical and Experimental Hypnosis, 46, 171-190.

Tomasson, K., Kent, D. \& Coryell, W. (1991) Somatization and conversion disorders: comorbidity and demographics at presentation. Acta Psychiatrica Scandinavica, 84, 288-293.

Uguz, S. \& Toros, F. (2003) Sociodemographic and clinical characteristics of patients with conversion disorder. Turk Psikiyatri Dergisi, 14, 51-58.

Webster, R. (1996) Why Freud Was Wrong. London: Fontana.

\title{
The Royal Australian and New Zealand College of Psychiatrists
}

\section{Philip Boyce ${ }^{1}$ and Nicola Crossland ${ }^{2}$}

1President, Royal Australian and New Zealand College of Psychiatrists, 309 Latrobe Street, Melbourne,
Victoria 3000, Australia; Professor of Psychiatry, Westmead Hospital, Wentworthville, New South Wales 2145,
Australia, email: pboyce@mail.usyd.edu.au

2Policy Research Officer, Royal Australian and New Zealand College of Psychiatrists

he vision of the Royal Australian and $\mathrm{New}$

Zealand College of Psychiatrists (RAN ZCP) is of 'a fellowship of psychiatrists working with and for the general community to achieve the best attainable quality of psychiatric care and mental health'. It is the principal organisation representing the specialty of psychiatry in Australia and $\mathrm{New}$ Zealand; it currently has around 2600 Fellows, who account for approximately $85 \%$ of psychiatrists in Australia and $50 \%$ of psychiatrists in N ew Zealand. The RAN ZCP sets the curriculum, accredits training and training programmes, and assesses trainee psychiatrists. In addition, it administers a continuing professional development programme for practising psychiatrists, has a role in policy development, publishes two scientific journals - the Australian and New Zealand Journal of Psychiatry and Australasian Psychiatry - and holds an annual scientific congress.

\section{Organisation and history}

General C ouncil is the governing body of the RAN ZCP. Its core functions are served by four boards: the Fellow ships Board, the Board of Practice Standards, the Board of Professional and Community Relations, and the Board of Research. Each board oversees committees. Sub-specialties of psychiatry are represented through faculties (the Faculty of C hild and Adolescent
Attempts have been made over the past century to abolish and then to reinstate the condition by using different labels, and conversion

hysteria continues to attract controversy.

\footnotetext{
Website http:// www.ranzcp.org/ publicarea/ public.asp
} 
Psychiatry, the Faculty of Psychiatry of O Id Age), sections (Section of C onsultation-Liaison Psychiatry, Section of Forensic Psychiatry, Section of Psychotherapy, Section of Social and Cultural Psychiatry, Section of Addiction Psychiatry, Section of N europsychiatry) and special interest groups. The RAN ZCP has branches in N ew Zealand and in each Australian state and the Australian Capital Territory.

The RAN ZCP began life in 1946 as the Australasian Association of Psychiatrists. There were 67 foundation members, all practising psychiatrists. The Asso ciation's inception closely followed the Second World War; the war may have been influential in its establishment, having led to an increase in the recognition of, and demand for, psychiatric treatment. Membership was limited to those with both medical and psychiatric qualifications: at this stage the Association had no role in the process by which people could enter the profession and did not admit trainees. Some of its other activities, how ever, remain the same to day: publication (in those days of the Australasian Psychiatric Quarterly) and an annual conference. The Association became the Australian and $\mathrm{N} \mathrm{ew}$ Zealand College of Psychiatrists in 1963, acquiring the 'Royal' prefix in 1977. The College's remit expanded to include a role in education and it became the gatew ay for doctors to become specialists in psychiatry (Rubenstein $\&$ Rubenstein, 1996).

\section{Becoming a Fellow: the RANZCP's training programme}

quality of

psychiatric service.
The RAN ZCP programme for postgraduate training in psychiatry is based on an apprenticeship model. Trainee psychiatrists must complete a minimum of 5 years' fulltime (or equivalent part-time) training in psychiatric practice. To register with the RAN ZCP as a trainee, applicants must:

- have satisfactorily completed at least 2 years' fulltime equivalent general medical training

- hold current registration as a medical practitioner in Australia, N ew Zealand or other approved country, state, territory or dependency

- be in good standing with the relevant medical registration board or equivalent approved body
- be selected to enter an approved basic training programme

- be appointed to an approved training post.

Basic training takes 3 years. The first year concentrates on the acquisition of knowledge and skills in phenomenology, interviewing, clinical assessment and the principles of management planning. The second and third years place an emphasis on the development of knowledge and skills in clinical management and teamwork. Assessment of basic training is via two case histories, and written and clinical examinations.

Advanced training involves 2 years' full-time equivalent supervised experience in clinical psychiatry or in an approved advanced training programme, and completion of core advanced training experiences. Self-directed learning and the processes used in continuing medical education are important for advanced training. $0 \mathrm{n}$ successful completion of all training requirements, trainees are eligible for election to Fellowship of the College.

The educational remit of the RAN ZCP extends beyond election to Fellowship. Its programme for continuing professional development provides a pathway for psychiatrists to review and develop professional practice and abilities, with the objective that the profession delivers the highest quality of psychiatric service.

\section{Providing strategic leadership and support in mental health policy}

In Australia and $\mathrm{N}$ ew Zealand, as in many other countries, recognition of mental health issues has increased in recent years. Table 1 gives an overview of psychiatry in Australia and $\mathrm{N}$ ew Zealand.

The RAN ZCP aims to inform and influence mental health policy by offering credible, objective and clinically informed advice and initiatives. It works in partnership with governments, consumer organisations, and other medical organisations. It publishes position statements and other guidelines on psychosocial issues in response to current events and for the information of its members and the wider public.

In both countries there is an under-supply of psychiatrists, and the shortage is particularly acute in rural

Table 1. An overview of psychiatry in Australia and New Zealand

\begin{tabular}{ll}
\hline Australia & New Zealand \\
\hline $\begin{array}{l}\text { Population } 20 \text { million; majority of European descent, } \\
2.2 \% \text { Aboriginal and Torres Strait Islanders }\end{array}$ & $\begin{array}{l}\text { Population } 4 \text { million; majority of European descent, } 15 \% \text { Maori, } \\
7 \% \text { Pacific Islanders }\end{array}$ \\
$\begin{array}{l}\text { Total health budget (2002) A } \$ 66.6 \text { billion } \\
\text { Mental health budget (2002) A } \$ 3.9 \text { billion }\end{array}$ & $\begin{array}{l}\text { Total health budget (2001-02) NZ\$6918 million } \\
12.1 \text { psychiatrists per } 100000 \text { population }\end{array}$ \\
$60 \%$ of psychiatrists work mainly in private practice, & 4.3 psychiatrists per 100000 population \\
the other $40 \%$ mainly in the public system & The majority of psychiatrists work in the public system
\end{tabular}

Sources: Australian Bureau of Statistics, Statistics New Zealand, Australian Institute of Health and Welfare, New Zealand M ental Health Commission. 
and remote areas. The RAN ZCP recognises that workforce shortages and difficulties in recruitment are significant and constitute a major challenge to service provision, and is attempting to improve recruitment into the profession.

Strengthening the psychiatric workforce involves clarification of the role of the psychiatrist. The RAN ZCP supports the role of the psychiatrist as a specialist treatment provider, and as a consultant and clinical leader within a multidisciplinary team.

With a shortage of psychiatrists, and with much mental healthcare in the primary sector, the RAN ZCP has formed partnerships with the Royal Australian College of General Practitioners, the Australian D ivisions of $G$ eneral Practice, consumer groups and the Australian government to develop a range of practical and systemic measures to improve liaison between psychiatry and general practice. Among these is the development of structures to allow psychiatrists to work in a consultant capacity, whereby general practitioners may refer their patients to a psychiatrist for an assessment and receive a management plan from the psychiatrist. This new practice will be supported by cross-discipline training workshops.

In a specialty which treats complex, multifactorial disorders, evidence-based principles are important in ensuring effective treatment. The RAN ZCP has recently published clinical practice guidelines on six common psychiatric conditions:

- schizophrenia

- bipolar disorder

- depression

- anorexianervosa

- panic disorder and agoraphobia

- self-harm.

These guidelines stem from an earlier RAN ZCP project, carried out between 1981 and 1991, which produced ten evidence-based clinical practice guidelines for the common mental disorders - the first set of guidelines to be developed for any specialty. Comprehensive guidelines for clinicians are published in the Australian and New Zealand Journal of Psychiatry (Boyce et al, 2003), and versions for consumers and carers are available from the College's website or in booklet form. The RAN ZCP, with the assistance of funding from the Australian and $\mathrm{N}$ ew Zealand governments, is currently beginning the process of implementing these guidelines.

Improvements in mental health systems can be made only with the participation of those who use mental health services. Aw are of this, the RAN ZCP invites consumer and carer representatives to sit on its Board of Professional and Community Relations, and is currently developing a broader policy of community engagement to inform the core areas of College business.
Looking ahead: community, workforce and international affairs

The RAN ZCP will build upon its existing practice to establish a programme of greater community participation, to use the lived experience of people with mental illness to inform the College's work, such as the training of psychiatrists, and in the ongoing professional development of RAN ZCP Fellows. Through engaging the community, the College hopes to make research partnerships to inform policy development and to advocate for improved and more accessible mental health services and psychiatric care.

The RAN ZCP aims to meet the challenge of mental health workforce shortages by improving recruitment into the profession. In addition, its training programme will broaden and support skills development in multidisciplinary practice, complex care coordination, specialised psychosocial interventions and leadership. Acquiring a basic understanding of, and respect for, the range of mental health disciplines is crucial during training and a key to ongoing professional collaboration. The College has also begun a programme to support psychiatrists trained overseas.

An important future focus for the RAN ZCP will be to establish and maintain collaborative working relationships internationally, particularly across the Asia-Pacific region. The College seeks to create closer links with neighbouring organisations and enhance public mental health promotion strategies in the region. To this end, an 0 ffice of International Relations is being established within the $O$ ffice of the President and the Chief Executive 0 ffice to review strategic directions, respond to international issues, oversee international projects and build international relations.

The RAN ZCP will be hosting the World Psychiatric Association (WPA) World Congress in Australia in 2007. The W PA Congress is held annually and is one of the largest psychiatric meetings, attracting over 5000 participants from around the world. The RAN ZCP, in partnership with the W PA, has proposed a W PA AsiaAustralasia Partnership Initiative for Mental $\mathrm{H}$ ealth to develop collaborations with membership so cieties in Asian countries and promote a programme for education and training to advance the best practices of clinical psychiatry. Such education and training aim to help member societies to improve and extend mental health service delivery to their citizens.

In both countries there is an undersupply of

psychiatrists, and the shortage is particularly acute in rural and remote areas. The RANZCP

recognises that workforce shortages and difficulties in recruitment are significant and constitute a major challenge to service provision, and is attempting to improve recruitment into the profession.

Royal Australian and New Zealand College of Psychiatrists.

Clinical Practice Guidelines for Consumers and Carers. Updated 21 March 2005: http:// www.ranzcp.org/ publicarea/ cpg.asp

\section{References}

Boyce, P., Ellis, P. \& Penrose-Wall, J. (2003) Introduction to the Royal Australian and $\mathrm{New}$ Zealand College of Psychiatrists clinical practice guidelines series. Australian and $\mathrm{New}$ Zealand Journal of Psychiatry, 37, 637-640.

Rubenstein, W. D. \& Rubenstein, H. L. (1996) Menders of the $\mathrm{M}$ ind: $\mathrm{A} \mathrm{H}$ istory of the Royal Australian and $\mathrm{New}$ Zealand College of Psychiatrists, 1946-1996. Melbourne: Oxford University Press. 